\title{
EFFECT OF FLUORIDE EXPOSURE THROUGH DRINKING WATER ON THE ORAL HEALTH STATUS AND INTELLIGENCE PROFILE OF SCHOOL CHILDREN OF DISTRICT UNA, HIMACHAL PRADESH: AN INTERIM ANALYSIS
}

\author{
Piyush Sharma1, Mitasha Singh², Dinesh Kumar ${ }^{3}$, Ashoo Grover", Ashok Kumar Bhardwaj5 \\ ${ }^{1}$ Senior Research Fellow, Department of Community Medicine, Dr. Rajendra Prasad Government Medical College, Himachal Pradesh. \\ ${ }^{2}$ Senior resident, Department of Community Medicine, Hamdard Institute of Medical Sciences and Research, New Delhi. \\ ${ }^{3}$ Assistant Professor, Department of Community Medicine, Dr. Rajendra Prasad Government Medical College, Himachal Pradesh. \\ ${ }^{4}$ Scientist, E, ICMR, New Delhi. \\ 5Professor and Nodal Officer, School of Public Health, Dr. Rajendra Prasad Government Medical College, Himachal Pradesh.
} ABSTRACT

\section{BACKGROUND}

This interim analysis of an ongoing project aims to study the association of fluoride levels with dental fluorosis and intelligence among children of 10-14 years of age in study area.

\section{MATERIALS AND METHODS}

The study was conducted in randomly selected 15 government high schools of District Una, Himachal Pradesh. The analysis of seven schools is being discussed with a sample size of 270. Dean's Fluorosis index was used to study fluorosis level and Intelligence test was conducted on students by using Raven's standard progressive matrices questionnaire.

Study Duration-Nine months.

\section{RESULTS}

Dental fluorosis was observed among $11.5 \%$ of students. It was higher among females $(12.4 \%)$ as compared to males (10.6\%). The intelligence level assessment of student showed that all of them were in the range of above average; about $83.3 \%$ of students were having grade III (Average) level of intelligence.

\section{CONCLUSION}

As the fluorosis level increased, the proportion of children with lower intelligence increased. Based on the findings, the chronic exposure to high levels of fluoride can be one of the factors that influence intellectual development.

\section{KEYWORDS}

Fluorosis, Intelligence Quotient, Adolescents.

HOW TO CITE THIS ARTICLE: Sharma P, Singh M, Kumar D, et al. Effect of fluoride exposure through drinking water on the oral health status and intelligence profile of school children of district Una, Himachal Pradesh: An interim analysis. J. Evolution Med. Dent. Sci. 2016;5(102):7484-7487, DOI: 10.14260/jemds/2016/1694

\section{BACKGROUND}

Fluorine is an important element in growth of teeth and prevents the enamel from dissolving under acidic conditions. Drinking water and sea food are good sources of Fluoride. Fluoride is beneficial to health if the concentration (CF) of the fluoride ion (F-) in drinking water is less than $1.5 \mathrm{mg} / \mathrm{L}$. Ingestion of excess fluoride, most commonly in drinkingwater, can cause fluorosis which affects the teeth and bones. Moderate amounts lead to dental effects, but long-term ingestion of large amounts can lead to potentially severe skeletal problems. Paradoxically, low levels of fluoride intake helps to prevent dental caries. The control of drinking-water quality is therefore critical in preventing fluorosis. World Health Organization (WHO) has set the upper limit of fluoride

Financial or Other, Competing Interest: None.

Submission 29-10-2016, Peer Review 08-12-2016,

Acceptance 14-12-2016, Published 22-12-2016.

Corresponding Author:

Dr. Piyush Sharma

Senior Research Fellow,

Department of Community Medicine,

Dr. Rajendra Prasad Government Medical College,

Kangra, Himachal Pradesh.

E-mail: piyush_rko@yahoo.co.in

DOI: $10.14260 /$ jemds $/ 2016 / 1694$ concentration in drinking water at $1.5 \mathrm{mg} / \mathrm{L}$ and in India the maximum permissible limit is $1 \mathrm{mg} / \mathrm{L}^{1}$

Known fluoride belts on land include: one that stretches from Syria through Jordan, Egypt, Libya, Algeria, Sudan and Kenya, and another that stretches from Turkey through Iraq, Iran, Afghanistan, India, northern Thailand and China. There are similar belts in the Americas and Japan. In these areas fluorosis has been reported. ${ }^{2}$ The available data suggest that 15 States in India are endemic for fluorosis (fluoride level in drinking water $>1.5 \mathrm{mg} / \mathrm{L}$ ), and about bout 62 million people in India suffer from dental, skeletal and non-skeletal fluorosis. Out of these; 6 million are children below the age of 14 years. $^{3}$

Introduction of systemic and topical fluorides into the prevention and control of dental caries denotes the most significant issue in dentistry. In the 1980s, it was established that fluoride controls caries mainly through its topical effect. ${ }^{4} \mathrm{~A}$ meta-analysis of 27 cross-sectional studies of children exposed to fluoride in drinking water, mainly from China, suggests an average IQ decrement of about seven points in children exposed to raised fluoride concentrations. ${ }^{5}$ There is paucity of literature published from the Indian subcontinent, which shows that fluoride exposure has an effect on the intellectual function of children. Data from previous studies could lend support to the hypothesis that 
interaction between fluoride, lead and arsenic could worsen the children's intelligence grade and thus indicate a need for further investigation. ${ }^{6}$

There is limited evidence on fluoride levels in water level across the country and so its association with dental fluorosis and intelligence of children. In addition, the fluoride levels in water bodies differ from region to region and are not uniform. Therefore, the present study aims to map the study area (District Una, Himachal Pradesh) into high and low fluoride area. Thereafter, the association of high and low fluoride levels with dental fluorosis and intelligence among children of 10-14 years of age will be studied in study area.

\section{MATERIALS AND METHODS}

District Una is in South western part of Himachal Pradesh and is situated in east of outer Shivaliks. It lies within North latitude 31017'52" and 31052'0" and East longitude 75058'2" and $76^{\circ} 28^{\prime} 25^{\prime \prime}$.Una district is bounded by the river Beas on the north and the river Sutlej in the east. The population of district according to census 2011 was 5,21,057 where 10-14 years of age contributed to $10.3 \%$ of population.

This is an interim analysis of an ongoing project which is being carried out in government high schools of district Una of Himachal Pradesh. There are total 42 high schools of district Una spreading over five blocks namely; Una, Amb, Haroli, Gagret, Dhundla. On an average, there are 40-50 school children of 10-14 years of age in each school and a total of 15 schools are being surveyed for the study purpose. In order to complete geographical coverage of study area, 3 schools were selected randomly (lottery method) from each of five blocks of the district $(3 \times 5=15)$. This interim analysis presents observations from seven schools in the period of nine months. Two schools selected from the two of the blocks and one each from the remaining three.

To detect $40.0 \%$ prevalence of malocclusion and $60.0 \%$ of prevalence of dental fluorosis, considering 1.5 relative risk ${ }^{7}$ at $95.0 \%$ confidence level and $80.0 \%$ study power, a sample size of 369 children is calculated. Based on $10.0 \%$ non-response, 405 children of age 10-14 years are being screened for oral hygiene, malocclusion and dental fluorosis. In order to keep reliable and relevant estimate, a sample size of 600 school children will be kept. These children are selected from all the government high schools based upon population proportion to size.

In the current analysis, data on 270 school children within the age group of 10-14 years from last six months (March through August 2016) studying at the selected government schools of study area were available. Prior consent was taken from all the school authorities and the parents of the children to conduct the survey. Those who did not consent to participate and children who are not enrolled in the school for the last 5-8 years were excluded from the analysis. Also, children who have a history of congenital or acquired neurological disorder or head injury were excluded from the analysis.

To assess the prevalence of fluorosis we used Dean's Fluorosis index. ${ }^{8}$ The dental checkup was performed by a dentist (Principal investigator) and his team which consisted of a medical social worker, and a health worker. The schools were mostly visited on Saturdays after taking appointment with the Principal as the students had more of free classes on this day of week. The four classes of the school ( $\left.5^{\text {th- }} 8^{\text {th }}\right)$ were included in the study. On an average, all the government schools included in the survey had around 15-16 children in each of the above-mentioned classes. The dentist examined all the students of these classes to achieve a sample size of 40 in each school. One school was visited twice to complete the sample size. However, taking into account child absenteeism, exclusion criteria and not consenting to participate we reached to a sample size of 270 .

Intelligence test was conducted on students by using Raven's standard progressive matrices questionnaire. ${ }^{9}$ The children's scores were converted to percentile and specific grades were allotted, based on the following criteria:

Grade I: Intellectually superior - If the score lies at or above the ninety-fifth percentile for that age group. Grade II: Definitely above average - If the score lies at or above the seventy-fifth percentile for that age group. Grade III: Intellectually average - If the score lies between the 25th and 75th percentile for that age group. Grade IV: Definitely below average in intellectual capacity - If the score lies at or below the 25th percentile for that age group. V: Intellectually impaired - If the score lies at or below the fifth percentile for that age group. The grades and intelligence are inversely related in the Raven's Standard Progressive Matrices.

Water sample was collected from the selected schools and tested for fluoride levels. The water sample was tested with the help of ion exchange method using specific F-electrode method. In the present study area, the source of the water supply is ground water which is lifted with pump and stored in large reservoirs. This method for water supply is implemented under the state government scheme "uthao peyjal pariyojna" (lift water scheme) to the entire district. The water sample was collected from the seven schools, from where the children were recruited. Chi square and standard error of difference of proportion is used to detect significant difference for proportion.

\section{Ethical Clearance}

Protocol has been reviewed and ethical clearance has been obtained from ethical committee of Dr. R. P. Govt. Medical College, Kangra at Tanda.

\section{RESULTS}

In the interim analysis, a total of 270 children were surveyed from seven schools along with collection of water sample for fluoride level. The water sample was collected from drinking water from where children were recruited. The place of water sample collected is shown in Table 1 indicating that the water sample collection was done from the same area at the inhabitant of the selected villages. (Table 1).

Dental fluorosis was observed among $11.5 \%$ of students. Its prevalence was found to be $10.6 \%$ in males and $12.4 \%$ among females. The severity for dental fluorosis was assessed and so far no single case of severe dental fluorosis was observed. Very mild-to-moderate dental fluorosis was observed in $4.7 \%$ and $6.2 \%$ had questionable status. (Table 2).

The intelligence level assessment of student showed that all of them were in the range of grade II to grade III, about 83.3\% of students were having grade III level of intelligence. The 
distribution for intelligence level was observed to be statistically different in both males and females. (Table 3).

Cross tabulation for intelligence and fluorosis level was done and none of the children with grade I and grade V level of intelligence was observed. (Table 4). Neither was there any subject with severe fluorosis level. So, they are excluded from the table 4. Grade II intelligence was compared against grade III and IV level separately. Fluorosis free category included $88.7 \%$ children with average intelligence. Majority of children were having grade III level of intelligence; it was observed as a dominant category across normal (94.6\%) to very mild level $(60.0 \%)$ of fluorosis as compared to grade II intelligence level. The difference was statistically significant across all levels of fluorosis. Below average intelligence was observed to be higher among very mild fluorosis level $(66.7 \%)$ as compared to above average level. Among the below average intelligent group, higher proportion was observed among normal fluorosis group (62.5\%). No significant difference was observed between grade IV and II level of intelligence with level of fluorosis among children.

\begin{tabular}{|c|c|c|}
\hline Serial. No & Place & Fluoride Content (ppm) \\
\hline 1 & Saloh & 0.57 \\
\hline 2 & Haroli & 0.42 \\
\hline 3 & Lalhri & 0.40 \\
\hline 4 & Mehtpur & 0.68 \\
\hline 5 & KutharKalan & 0.63 \\
\hline 6 & Gagret & 0.41 \\
\hline 7 & Batoli & 0.52 \\
\hline \multicolumn{3}{|c|}{ Table 1. Fluoride Content of Water Sample } \\
collected from Selected Government Schools \\
\hline
\end{tabular}

\begin{tabular}{|c|c|c|c|c|}
\hline $\begin{array}{c}\text { Fluorosis } \\
\text { Parameter }\end{array}$ & $\begin{array}{c}\text { Male N } \\
\text { (\%) }\end{array}$ & $\begin{array}{c}\text { Female } \mathrm{N} \\
(\%)\end{array}$ & $\begin{array}{l}\text { All N } \\
\text { (\%) }\end{array}$ & $\begin{array}{c}\mathbf{p} \\
\text { value }\end{array}$ \\
\hline Normal (0) & $126(89.3)$ & $113(87.5)$ & $239(88.5)$ & 0.65 \\
\hline $\begin{array}{c}\text { Questionable } \\
(0.5)\end{array}$ & $8(5.6)$ & $9(6.9)$ & $17(6.2)$ & 0.66 \\
\hline Very mild (1) & $4(2.8)$ & $5(3.8)$ & $9(3.3)$ & 0.63 \\
\hline Mild (2) & $2(1.4)$ & $1(0.7)$ & $3(1.1)$ & 0.61 \\
\hline Moderate (3) & $1(0.7)$ & $1(0.7)$ & $2(0.3)$ & 0.95 \\
\hline Severe (4) & $0(0)$ & $0(0)$ & $0(0)$ & NA \\
\hline Total & $\begin{array}{c}141 \\
(100)\end{array}$ & $\begin{array}{c}129 \\
(100)\end{array}$ & $\begin{array}{c}270 \\
(100)\end{array}$ & \\
\hline \multicolumn{5}{|c|}{$\begin{array}{l}\text { Table 2. Severity of Dental Fluorosis in the Examined } \\
\text { School Children }\end{array}$} \\
\hline
\end{tabular}

\begin{tabular}{|c|c|c|c|c|}
\hline Parameter & $\begin{array}{c}\text { Male N } \\
(\%)\end{array}$ & $\begin{array}{c}\text { Female N } \\
(\%)\end{array}$ & All (\%) & $\begin{array}{c}\text { p } \\
\text { value }\end{array}$ \\
\hline Grade 1 & $0(0)$ & $0(0)$ & $0(0)$ & - \\
\hline Grade 2 & $12(8.5)$ & $9(6.9)$ & $21(7.7)$ & 0.63 \\
\hline Grade 3 & $118(83.6)$ & $107(82.9)$ & $225(83.3)$ & 0.87 \\
\hline Grade 4 & $11(7.8)$ & $13(10)$ & $24(8.8)$ & 0.64 \\
\hline Grade 5 & $0(0)$ & $0(0)$ & $0(0)$ & - \\
\hline Total & $\begin{array}{c}141 \\
(100.0)\end{array}$ & $\begin{array}{c}129 \\
(100.0)\end{array}$ & $\begin{array}{c}\mathbf{2 7 0} \\
(100.0)\end{array}$ \\
\hline \multicolumn{6}{|c|}{ Table 3. Intelligence Assessment in Examined School } \\
\hline \multicolumn{6}{|c|}{ Children } \\
\hline
\end{tabular}

\begin{tabular}{|c|c|c|c|c|c|c|}
\hline \multirow[b]{2}{*}{$\begin{array}{c}\text { Fluorosis } \\
\text { Level }\end{array}$} & \multicolumn{6}{|c|}{ Intelligence Level } \\
\hline & 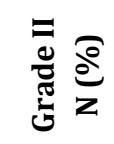 & 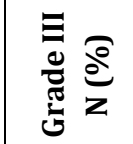 & $\frac{\stackrel{0}{\Xi}}{\frac{\pi}{3}}$ & 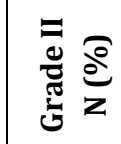 & 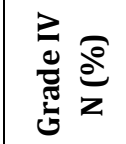 & ب⿱ \\
\hline Normal & $12(5.4)$ & $212(94.6)$ & 0.00 & $12(44.4)$ & $15(55.6)$ & 0.71 \\
\hline Questionable & $5(38.4)$ & $8(61.6)$ & 0.00 & $5(55.6)$ & $4(44.4)$ & 0.54 \\
\hline Very mild & $2(40.0)$ & $3(60.0)$ & 0.01 & $2(33.3)$ & $4(66.7)$ & 0.48 \\
\hline Mild & $1(50.0)$ & $1(50.0)$ & 0.02 & $1(50.0)$ & $1(50.0)$ & 0.92 \\
\hline Moderate & $1(50.0)$ & $1(50.0)$ & 0.02 & $1(100)$ & 0 & 0.28 \\
\hline Total & $21(8.5)$ & 225 (91.5) & & $21(46.7)$ & $24(53.3)$ & \\
\hline & & & & I & Level & \\
\hline
\end{tabular}

\section{DISCUSSION}

In the present study, the proportion of students with questionable fluorosis parameter is $6.2 \%$, very mild and mild dental fluorosis as per Dean's index was 3.3\% and 1.1\% respectively. This estimate in our study is very less as compared to other studies done in other states of India. A higher prevalence of $91.2 \%$ was reported from the Punjab, ${ }^{10}$ 61-66.7\% from Birbhum, West Bengal $11,71 \%$ from Nalgonda in south ${ }^{12}$ and $45.7 \%$ from Rajasthan. ${ }^{13}$ The present study did not show severe fluorosis in any of the students and only $0.2 \%$ of students had moderate fluorosis.

The prevalence among girls was more $(12.4 \%)$ than boys $(10.6 \%)$. Among girls, questionable parameter in $6.9 \%$, very mild $3.8 \%$, mild $0.7 \%$, and severe form was noted to be nil whereas among boys, questionable $5.6 \%$, very mild $2.8 \%$, mild $1.4 \%$, and severe form was again not presented by them. Moreover, this is consistent with the results of other studies conducted in Kerala, where higher prevalence was reported among girls. ${ }^{14}$ On the contrary, another study conducted among children of Tamil Nadu and Nalgonda, prevalence was reported more among boys than girls. ${ }^{12,15}$

Majority of the children were in intellectually average intelligence group (grade III: 83.3\%). Higher proportion of boys belonged to intellectually above average and average intelligence group as compared to girls; however, the difference was not significant. In psychology books also, gender is mentioned as a nonrelated factor to IQ. Similar results were reported by Xiang et al from China ${ }^{16}$ and Khan et al from Lucknow, 17 India. However, majority of children from Lucknow were above average intelligence (45.7\%) ${ }^{17}$; however, this was conducted on relatively lower age group (6-13 years). Another similar study from Iran showed around $28 \%$ of average intelligence children (7-9 years) and $9 \%$ above average and no significant difference between male and females. ${ }^{18}$ An observation of decreasing IQ with increasing age has been discussed by Xiang et al, but reason is still not clear. Possibly, the total intake of fluoride $/ \mathrm{kg}$ body weight per day or lifetime was the main cause, also adolescence is a sensitive period for the effect of fluoride on children's intelligence development. ${ }^{16}$ The reason for relatively lower proportion of IQ level in our study area could be due to its rural background, low socioeconomic status and nutritional status. However, these confounders have not been accounted for in this interim analysis. They will be accounted for in the final report. 
In the current analysis, we compared normal and below normal intelligence with above normal across the various fluorosis levels. As the fluorosis level increased, the proportion of children with lower intelligence increased. Xiang et al also found a significant inverse concentrationresponse relationship between the fluoride level in drinking water and the IQ of children. ${ }^{16}$ Khan et al observed that majority of the fluorosis free children $(76.3 \%)$ had an IQ grade 2,17 whereas our study reported $88.7 \%$ grade 3 children in the same group. Khan et al., also reported that with increase in the grade of fluorosis, a trend of increase in the IQ grade (decrease in intellectual capacity) was observed indicating a strong correlation between fluorosis grade. ${ }^{17}$ Saxena et al and Shivaprakash et al in their study have also demonstrated that intellectual capacity of children decreases with increase in the fluorosis grade.6, ${ }^{19}$ Data from previous studies support to the hypothesis that interaction between fluoride, lead, and arsenic could worsen the children's intelligence grades, ${ }^{20}$ and thus, indicate a need for further investigation. Guan et al demonstrated that the contents of phospholipids and ubiquinone are altered in the brain of rats affected by chronic fluorosis, and therefore changes in membrane lipids could be a cause of this disorder. ${ }^{21} \mathrm{~A}$ principal ground for reduced intelligence in human children exposed to high levels of fluoride is its ability to cross the blood brain barrier, producing biochemical and functional impairment of the nervous system during prenatal and development periods of early childhood and childhood. IQ, however, is known to be influenced by many factors, including differences in biological susceptibility, environmental conditions, and measurement errors. ${ }^{22}$ Our study area lies in the foothills of Dhauladhar ranges, which are endemic for hypothyroidism. In a low iodine area, impairment of intelligence could occur through the development of hypothyroidism or clinical/subclinical cretinism.

\section{CONCLUSION}

Data from this interim analysis supports that children exposed to fluoride are at risk for impaired development of intelligence. After the complete data is analysed the true association will be available.

\section{Recommendations}

Millions of children around the world are exposed to high concentration of fluoride in water, and are therefore, potentially at risk. An urgent attention is needed to protect the upcoming generation.

\section{REFERENCES}

1. World Health Organization. Guidelines for drinking water quality. Geneva: WHO 2004.

2. World Health Organization. Water related diseases: fluorosis. Geneva: WHO 2001.

3. Susheela AK. Fluorosis: Indian scenario: a treatise on fluorosis. Fluorosis research and rural development foundation. New Delhi, India 2001.

4. Buzalaf MA, Pessan JP, Honório HM, et al. Mechanisms of action of fluoride for caries control. Monogr Oral Sci 2011;22:97-114.

5. Choi AL, Sun G, Zhang Y, et al. Developmental fluoride neurotoxicity: a systematic review and metaanalysis. Environ Health Perspect 2012;120(10):1362-8.
6. Saxena S, Sahay A, Goel P. Effect of fluoride exposure on the intelligence of school children in Madhya Pradesh, India. J Neurosci Rural Pract 2012;3(2):144-9.

7. Kotecha PV, Patel SV, Bhalani KD, et al. Prevalence of dental fluorosis and dental caries in association with high levels of drinking water fluoride content in a district of Gujarat, India. Indian J Med Res 2012;135(6):873-7.

8. Centre for Disease Control. Fluoridation of drinking. MMWR 1998;48:933-40.

9. Department of Psychology, Huadong Normal University. Manual of Combined Raven's Test-the Rural China, 1989.

10. Shashi A, Bhardwaj M. Prevalence of dental fluorosis in endemic area of Punjab, India. Biosci Biotech Res Comm 2011;4(2):155-63.

11. Majumdar KK. Health impact of supplying safe drinking water containing fluoride below permissible level on fluorosis patients in a fluoride-endemic rural area of West Bengal. Indian J Public Health 2011;55(4):303-8.

12. Shekar C, Cheluvaiah MB, Namile D. Prevalence of dental caries and dental fluorosis among 12 and 15 years old school children in relation to fluoride concentration in drinking water in an endemic fluoride belt of Andhra Pradesh. Indian J Public Health 2012;56(2):122-8.

13. Choubisa SL. Endemic fluorosis in southern Rajasthan, India. Fluoride 2001;34(1):61-70.

14. Chandrashekar J, Anuradha KP. Prevalence of dental fluorosis in rural areas of Davangere, India. Int Dent J 2004;54(5):235-9.

15. Saravanan S, Kalyani C, Vijayarani MP, et al. Prevalence of dental fluorosis among primary school children in rural areas of Chidambaram Taluk, Cuddalore District, Tamil Nadu, India. Indian J Community Med 2008;33(3):146-50.

16. Xiang Q, Liang Y, Chen B, et al. Analysis of children's serum fluoride levels in relation to intelligence scores in a high and low fluoride water village in China. New Zealand: The International Society for Fluoride Research 2011;44(4):191-4

17. Khan SA, Singh RK, Navit S, et al. Relationship between dental fluorosis and intelligence quotient of school going children in and around Lucknow district: a crosssectional study. Journal of Clinical and Diagnostic Research 2015;9(11):ZC10-5.

18. Poureslami HR, Horri $A$, Khoramian $S$, et al. Intelligence quotient of 7 to 9 year-old children from an area with high fluoride in drinking water. Journal of Dentistry and Oral Hygiene 2011;3(4):61-4.

19. Shivaprakash PK, Ohri K, Noorani H. Relation between dental fluorosis and intelligence quotient in school children of Bagalkot district. Journal of Indian Society of Pedodontics and Preventive Dentistry 2011;29(2):11720.

20. Rocha-Amador D, Navarro ME, Carrizales L, et al. Decreased intelligence in children and exposure to fluoride and arsenic in drinking water. Cad Saude Publica 2007;23(4):S579-87.

21. Guan ZZ, Wang YN, Xiao KQ, et al. Influence of chronic fluorosis on membrane lipids in rat brain. Neurotoxicol Teratol 1998;20(5):537-42.

22. Dash JP, Sarangi A, Singh DK. Spatial variability of ground water depth and quality parameters in the national capital territory of Delhi. Environ Manage 2010;45(3):640-50. 